\title{
Círculos de cooperação, usos do território das cidades e cultura popular no Brasil
}

\begin{abstract}
Alex Manetta ${ }^{1}$
Resumo: Propõe-se uma reflexão acerca dos círculos de cooperação animados pela ação espontânea. Ao se associarem às divisões sociais e territoriais ascendentes do trabalho, esses círculos promovem usos flexíveis das cidades, revelando a emergência de racionalidades não-hegemônicas geradas na ordem dos lugares. Por meio da observação de círculos especializados na elaboração/circulação de bens culturais de conteúdo não-globalizado, objetiva-se uma aproximação à sua manifestação empírica, ressaltando seus potenciais como matrizes para o desenho de políticas públicas e comunitárias. Partindo de um conceito dinâmico e abrangente de espaço geográfico, dá-se enfoque aos circuitos espaciais de produção e aos usos do território pela cultura, procedimento que possibilita a consideração dos círculos de cooperação da cultura popular como um conjunto de contrafinalidades direcionadas à rupturas com a rigidez racional hegemônica, proporcionando conhecimentos práticos e atualizados sobre a realidade dos lugares e do mundo.
\end{abstract}

Palavras-chave: Usos flexíveis da cidade; ação espontânea; círculos de cooperação da cultura popular.

\section{Círculos de cooperación, usos del territorio de las ciudades y cultura popular en Brasil}

Resumen: Se propone una reflexión sobre los círculos de cooperación animados por la acción espontánea. $\mathrm{Al}$ asociarse con las divisiones sociales y territoriales ascendentes del trabajo, estos círculos promueven usos flexibles de las ciudades, revelando la emergencia de racionalidades no-hegemónicas generadas en los lugares. A través de la observación de círculos especializados en la elaboración/circulación de bienes culturales con contenido noglobalizado, se objetiva acercarse a su manifestación empírica, destacando sus potencialidades como matrices para el diseño de políticas públicas y comunitarias. Partiéndose de un concepto dinámico y comprensivo del espacio geográfico, se enfoca a los circuitos espaciales de producción y a los usos del territorio por la cultura, procedimiento que permite considerar a los círculos de cooperación de la cultura popular como un conjunto de contra-fines direccionados a rupturas con la rigidez racional hegemónica, aportando conocimientos prácticos y actualizados sobre la realidad de los lugares y del mundo.

Palabras-clave: Usos flexibles de la ciudad; acción espontánea; círculos de cooperación de la cultura popular.

\section{Cooperation circles, uses of the cities' territory and popular culture in Brazil}

Abstract: We propose a reflection about the cooperation circles animated by spontaneous actions. By associating themselves with the ascending social and territorial divisions of labor, these circles promote flexible uses of the cities, revealing the emergence of non-hegemonic rationalities, generated in the order of places. Through the observation of specialized circles in the elaboration/circulation of popular cultural goods, the objective is to approach their empirical manifestation, highlighting their potential as matrixes for the design of public and community policies. Starting from a dynamic and comprehensive concept of geographical space, the focus is on spatial circuits of production and the uses of territory by the culture. This procedure makes it possible to consider popular culture cooperation circles as a set of counter-purposes aimed at breaking with the rigidity of hegemonic rationality, providing practical and updated knowledge about the reality of places and the world.

Keywords: Flexible uses of the city; spontaneous action; cooperation circles of popular culture.

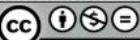

DOI: https://doi.org/10.26512/patryter.v4i8.31851

Como citar este artigo: Manetta, A. (2021). Círculos de cooperação, usos do território das cidades e cultura popular no Brasil. PatryTer - Revista Latinoamericana e Caribenha de Geografia e Humanidades, 4(8), 76-88. DOI: https://doi.org/10.26512/patryter.v4i8.31851

Recebido: 30 de maio de 2020. Aceite: 09 de setembro de 2020. Publicado: 01 de setembro de 2021 .

${ }^{1}$ Professor-colaborador do programa de pós-graduação em Estudos de População do ICSHu/UAEH (Hidalgo, México). ORCID: https://orcid.org/0000-0002-5558-0845.E-mail: alexmanetta@hotmail.com. 


\section{Introdução}

\section{E fiquei pensando: porque insistimos tanto e durante tanto tempo em participar desse clube $[a$ Humanidade], que na maioria das vezes só limita a nossa capacidade de invenção, criaşão, existência e liberdade? Será que não estamos sempre atualizando aquela nossa velha disposição para a servidão voluntária? (Krenak, 2019, p. 13).}

Conhecer as cidades constitui fundamento para um amplo e profundo vislumbre sobre o território usado brasileiro, sobretudo, quando um avançado processo de urbanização/metropolização reforça a concentração espacial da população, dos capitais, dos processos de decisão política e de difusão cultural. Para além das ações hegemônicas de ordem global que comandam o transcurso da reprodução material e simbólica das cidades, é necessário um olhar relativo à ação popular, cuja prática leva ao encontro de solidariedades e formas de cooperação apoiadas em racionalidades nãohegemônicas elaboradas na ordem dos lugares (Santos et al., 2000).

Frente situações de exclusão, indivíduos e coletividades demonstram respostas criativas, atuando rumo a uma maior integração social, dando expressão à flexibilidade tropical vigente no Brasil urbano. A estrutura das cidades, mesmo que parcialmente enrijecida, permite a todo instante a criação e a adaptação de relações sociais, o abandono de antigos traços culturais e a assimilação de conteúdos novos. Essa metamorfose cria uma ampla variedade de ofícios e uma multiplicidade de combinações, em um quadro ocupacional móvel no qual cada agente tende a exercer diferentes atividades, de acordo com a conjuntura, emergindo, assim, divisões do trabalho geradas desde baixo e sustentadas em seus respectivos meios geográficos. Através da maleabilidade e da capacidade de adaptação, são criados e recriados círculos de solidariedade que tomam a cidade como uma formaconteúdo, expressando relações sociais horizontalmente estabelecidas e usos criativos dos sistemas de objetos presentes (Santos, 1996).

Para que vicejem forças menos modernas, relativas aos setores populares urbanos, modos inéditos de convivência são gerados e novas formas de trabalho são aperfeiçoadas. A própria exclusão, evidenciada pelas desigualdades socioterritoriais, exige a transformação de impulsos de ordem global pela cultura e economia dos lugares, como um aspecto da política que se dá independentemente de organizações oficiais. Nesse processo, as heranças do passado são condimentadas pelas novidades e pelo sentimento de urgência, essa consciência do contemporâneo que é também motor do conhecimento (Santos, 2000). Ao proporcionar experiências criativas e comunicativas, a ação popular privilegia modos de pensar distintos daqueles oriundos da razão econômica instrumental, emergindo como um conhecimento prático e atualizado dos lugares, capaz de propiciar modelos culturais e de sociabilidade não orientados pelo mercado, mas com vistas no bem-estar de mais amplas parcelas da população (Santos et al., 2000).

Admite-se a existência de duas situações-tipo em todas as grandes cidades brasileiras, entre as quais nota-se um sem-número de situações intermediárias. De um lado, há uma dinâmica explicitamente globalizada e produzida desde cima, e de outro lado, uma dinâmica produzida desde baixo, que representa os setores populares. Sendo assim, existe também uma especialização do trabalho desde cima descendente - e outra desde baixo - ascendente, de modo que a cidade constitui um grande sistema produzido pela superposição de diversos subsistemas, que criam outros tantos sistemas de cooperação. Nas atuais condições de globalização, todos esses subcírculos - ou subsistemas - tendem à especializações de naturezas várias (Santos, 1996).

Com o fim de contribuir com o estudo da ação espontânea, propõe-se uma reflexão acerca dos círculos de cooperação cuja existência expressa divisões sociais e territoriais do trabalho criadas desde baixo, emergindo como um conjunto de contrafinalidades geradas na ordem dos lugares. De modo específico, objetiva-se realizar uma aproximação à manifestação empírica dos círculos de cooperação da cultura popular, através da observação de coletividades e meios especializados na elaboração/difusão de bens culturaisii de conteúdo não-globalitário. Já que esses círculos representam inúmeras formas possíveis de ação e de solidariedade, realiza-se um esforço também no sentido de ressaltar seus potenciais como matrizes para o desenho de intervenções públicas e comunitárias.

Com o intuito de iniciar essa reflexão, partese de um conceito dinâmico e abrangente de espaço geográfico. O espaço geográfico, entendido como um conjunto indissociável, solidário e contraditório de sistemas de objetos e sistemas de ações, pode ser definido também como a relação ininterrupta entre uma tecnoesfera - a base material - e uma psicoesfera - a base imaterial da formação de sentidos. Esse conceito encontra seus princípios filosóficos na existência de uma dialética entre o domínio do homem pela matéria trabalhada e o domínio da 
matéria pelo homem, constituindo-se uma totalização imperfeita buscando sempre totalizar-se, representando uma abstração cuja concreticidade é reconhecida nas paisagens, cidades e territórios (Santos, 1996).

Enquanto materialização do espaço geográfico, as cidades representam a realidade presente que dá sentido ao fenômeno urbano, reunindo sistemas de objetos de variadas idades e procedências, animados por uma enorme gama de relações sociais e econômicas. Exprimem um conjunto material regido por intencionalidades, como formas-conteúdo que abrigam a coexistência e o debate. Ao reunirem uma ampla diversidade de agentes e objetos, as cidades apresentam-se como lócus privilegiados desse processo, pois, é onde a complexidade de produtos e subprodutos da modernidade se complementa e os sujeitos urbanos se transformam, gerando a inteligência e o estímulo intelectual (Souza, 1997).

Os sistemas de objetos condicionam a forma como se dão as ações, ao mesmo tempo em que as ações são realizadas sobre objetos preexistentes, ou levam à criação de novos objetos, possibilitando uma constante reprodução física e social. A ação altera o valor do objeto, ainda que materialmente seja o mesmo, pois, a teia de relações em que está inserido opera sua metamorfose, fazendo com que seja substancialmente outro. Já o agente dessa transformação, ao imprimir uma ação sobre o objeto, transforma-se a si mesmo e ao seu entorno, pois, tanto as ações quanto os objetos só adquirem significação quando contextualizados em seu meio, criando-se, assim, sempre, novas geografias (Santos, 1996).

Considerando que essa dinâmica é constituída não apenas por fluxos materiais, mas, sobretudo, por fluxos imateriais (ordens, mensagens, crenças e ideologias), são reveladas inteligências que reúnem objetos, agentes e processos localizados em diferentes partes do território. Tais condições são expressas pela formação de circuitos espaciais de produção, definidos pela circulação de bens e de produtos, mediante, porém, o estabelecimento de verdadeiros círculos de cooperação, cuja observação demonstra o uso diferenciado do território por parte de empresas, instituições, indivíduos e coletividades. A constatação desses fatos permite uma compreensão da hierarquia dos lugares vinculada às divisões sociais e territoriais do trabalho, instituídas segundo uma articulação entre fenômenos vigentes em diferentes níveis de análise, desde o global até o nível dos lugares (Santos \& Silveira, 2001).
Ao longo do tempo, cada lugar é alvo de sucessivas divisões do trabalho. Mas, esse mesmo lugar, visto em um determinado momento, acolhe simultaneamente várias divisões do trabalho. Como essas divisões não se realizam independentemente dos fluxos, superpõem-se distintos circuitos espaciais de produção, criando-se solidariedades entre elementos novos e herdados, próximos e distantes, que a cada momento histórico assimilam diferentes níveis de solidariedade técnica e social do trabalho. Sendo assim, para além da cooperação vertical entre atividades realizadas ao mesmo tempo em distintos lugares, é preciso tomar em conta as cooperações horizontais, manifestas como um conjunto de conhecimentos produzidos desde os lugares onde se expressam (Santos e Silveira, 2001, p. 100).

Ao serem atingidos pelos vetores da modernidade, os lugares ganham uma porção de racionalidade hegemônica, cuja propagação é veloz e heterogênea. Essa razão passa a coexistir com um sem-número de contra-racionalidades, mais ou menos lentas, que variam entre as diversas coletividades e os diferentes subespaços. Consequentemente, os lugares não são apenas quadros de vida cotidiana, mas espaços vividos e de experiência sempre renovada que acolhem tanto as novidades como as heranças do passado, através de processos que possibilitam indagações sobre $\mathrm{O}$ presente e o futuro, gerando, assim, reflexões reveladoras acerca do mundo (Santos, 2000).

Essa informação endógena, nutrida pela força da contiguidade e do acontecer homólogo, constitui a possibilidade de dinamizar-se pela base a economia e a sociedade, de modo que fundamenta também as divisões sociais e territoriais do trabalho. Famílias de técnicas consideradas obsoletas são com frequência a estrutura desse labor de produzir e distribuir informação nos lugares, conforme demonstram as cooperativas e as associações de bairro, as rádios locais e os jornais comunitários, criando-se as bases para uma coesão social a serviço de benefícios coletivos. Haverá sempre o risco de uma ação espacialmente localizada tornar-se funcional para a ordem global. No entanto, com frequência, são descobertos, acima dos conflitos, interesses comuns que tendem a conduzir a uma nova consciência política, apoiada em uma densidade comunicacional cooperativa, solidária, dinâmica e transformadora (Santos \& Silveira, 2001).

Quem, nas cidades, possui acesso à velocidade e à fluidez proporcionadas pelas verticalidades, podendo, assim, percorrê-las e esquadrinhá-las, acaba por ver pouco dos lugares e do mundo. Sua comunhão com as imagens é 
frequentemente pré-fabricada e seu conforto vem exatamente do convívio com essa fábula. Já os homens lentos, para quem tais imagens são miragens, não podem, por muito tempo, estar em fase com esse imaginário artificialmente construído, escapando, assim, ao totalitarismo da racionalidade hegemônica. Desse modo, são os pobres que, nas cidades, geram a consciência e mais fixamente olham para o futuro, concebendo formas de ação capazes de consolidar uma admirável diversidade de solidariedades e de modelos culturais (Santos, 1996).

Com intuito de avançar na reflexão sobre as relações entre a ação espontânea, a emergência de razões não-hegemônicas constituídas na ordem dos lugares e sua manifestação através de círculos de cooperação da cultura popular, são descritos os procedimentos adotados. No Item 2 são aludidos dois tipos de ação que animam as cidades e dão sentido ao fenômeno urbano contemporâneo, cuja existência se vincula, de um lado, às ações estritamente geridas e administradas, vigentes segundo uma ordem globalizada, e de outro, às ações espontâneas geradas nos lugares. Na sequência, são destacados os circuitos espaciais de produção e os usos do território das cidades pela cultura, seja como uma contra-finalidade ou como veículo da razão econômica. Esse procedimento proporciona avanços na reflexão sobre a emergência de sistemas de objetos e de ações constituintes de verdadeiros círculos de cooperação da cultura popular (Item 3). Por último, são apresentadas as considerações finais (Item 4) e as referências utilizadas (Item 5).

\section{Circuitos espaciais de produção, círculos de cooperação e usos do território das cidades pela cultura.}

No âmbito da dinâmica econômica tornada global, as cidades brasileiras integram pontos de redes cuja presença influencia o quotidiano de relações próximas e também distantes. Nessas condições, a difusão e a incorporação de técnicas, objetos, ideias e hábitos exógenos aos lugares, elevam-se a uma amplitude jamais vista. A presença desses sistemas, como expressão do espaço reticular, tende a ser de uso exclusivo das grandes empresas e dos poderes públicos que comandam os processos mais significativos de ordenamento urbano e territorial. Esse conjunto de pontos forma um espaço vertical de fluxos e compõe um subsistema dentro do espaço total. O sistema de produção que se serve dessas verticalidades exige a velocidade, no entanto, apenas os agentes que participam plenamente do processo são beneficiários do tempo rápido, enquanto os demais raramente tiram todo o proveito proporcionado pela fluidez (Santos, 1996).

Ao constituir-se de uso seletivo, o espaço reticular contempla somente pontos e áreas que interessam ao fluxo e acúmulo de capital, excluindo e desvalorizando a totalidade do ambiente construído, esse retrato da diversidade das classes sociais, das diferenças de renda e dos modelos culturais. Em consequência, as cidades revelam seções privilegiadas pelas demandas das grandes empresas, adequadas aos modelos organizacionais capazes de efetivar maior precisão em suas ações. Simultaneamente, observa-se a expressão do espaço total - ou o espaço de todos os homens, coeso preferencialmente em função da contiguidade, das relações interpessoais e da coexistência. A essa manifestação agregam-se todas aquelas atividades que imprimem vivacidade aos interstícios das redes, cuja dinâmica se assenta no trabalho intensivo, em capitais reduzidos, na socialização e na co-presença, associando-se à organização horizontal que funda a escala do cotidiano e do tempo lento (Santos, 1994).

Essa diversidade revela uma modernização incompleta, que inclui tanto sistemas densos em ciência e tecnologia quanto objetos resultantes da experiência prática. Já o acesso desigual às infraestruturas, informações e serviços, expõe uma seletividade no uso do espaço urbano, como expressão das desigualdades socioterritoriais. Como reação, manifestam-se maleabilidades que permitem a utilização de espaços desvalorizados pelo capital como abrigos de contra-finalidades. A existência dessa complexidade permite não só a coexistência, mas, sobretudo, a complementariedade entre tempos e atividades que concretizam a totalidade do fenômeno urbano. Ao reunir todas as diferenças e as condições para a convivência entre circunstâncias tão desiguais, as cidades representam um requisito e ao mesmo tempo a possibilidade de acolhimento para todos os tipos de ação, o que permite uma ampla cooperação entre indivíduos, coletividades, instituições e empresas, efetivando-se novas racionalidades e múltiplas possibilidades de uso do território das cidades (Santos, 1994).

Reconhece-se a existência de uma pluralidade de ações que modificam a cidade e levam à ressignificação do fenômeno urbano. Essa diversidade foi agregada por Ribeiro (2000) em dois tipos, cujo caráter contraditório e complementar ajuda a salientar as relações dialéticas observáveis na dinâmica do espaço geográfico. As ações estritamente geridas e administradas articulam-se ao fluxo de ordens e de mensagens que corroboram com a razão econômica global. Ao penetrarem o tecido social 
através de redes de estímulo cultural, adequam o comportamento geral à reprodução sistêmica do consumo.

Esse tipo de ação revela sua condensação material por meio de objetos com elevada densidade técnica, estruturas cuja existência favorece fluxos articulados de mensagens, mercadorias, capitais e pessoas. A presença desses fixos e fluxos, constituídos a partir de ações que carregam enormes cargas de racionalidade econômica, corresponde ao domínio de circuitos espaciais globalizados de produção. Pela influência política, social e econômica de seus agentes, assim como pelo privilégio referente ao controle das principais redes de produção e de processamento da informação, seus promotores possuem a possibilidade de instalar sistemas de objetos de maneira que se tornem eficazes, prática que induz à especialização funcional dos lugares e permite a tomada de ações racionais sobre espaços igualmente racionalizados (Santos, 1996).

Ressalta-se a relação existente entre a estrutura produtiva presente nas cidades e as redes técnicas do território, que através dos meios de comunicação constituem elementos fundamentais na manutenção e expansão de mercados consumidores. Nessa dinâmica, a psicoesfera frequentemente se adianta à tecnoesfera, pois, enquanto alguns sistemas de objetos não chegaram efetivamente aos lugares, muitas vezes já chegaram as ondas eletromagnéticas carregadas de ideologias e de intencionalidades, estimulando a crença no desenvolvimento econômico como meio de melhoria das condições de vida, através da ampliação das promessas de consumo, justificando e consolidando a prática da racionalidade capitalista na quase totalidade do território brasileiro (Ribeiro, 1991).

Em um momento no qual as disparidades entre as ideias veiculadas e a realidade observada orientam percepções confusas sobre a vida cotidiana, o domínio sobre os meios de produção e divulgação da informação apresenta-se como um fator básico na manutenção do status quo (Santos, 2000). Por isso, as ações estritamente geridas e administradas desempenham um importante papel na mediação entre produção e consumo, chegando mesmo a definir culturalmente a identidade dos consumidores (Ribeiro, 1991).

À produção e distribuição de bens, antecipam-se a concepção, o controle, a coordenação, a previsão e o marketing. Antongiovanni (2001), ao abordar esse fato, faz referência à cultura como veículo da racionalidade econômica, já que os setores globalizados da economia se expandem em consonância com um tipo de expressão cultural capaz de promover, justificar e dinamizar extensos circuitos espaciais de produção e complexos círculos de cooperação.

$\mathrm{Na}$ economia tornada global, os circuitos espaciais de produção instalam-se em níveis superiores de complexidade, possibilitando a cooperação entre agentes e processos localizados em diferentes partes do território, pois, não basta apenas produzir, é indispensável colocar a produção em movimento, de modo que a circulação preside a produção. Os fluxos decorrentes passam a ser mais intensos, mais extensos e mais seletivos, quando a expansão dos fixos produtivos leva ao aumento dos fluxos que, por sua vez, exigem a existência de fixos para balizar seu próprio movimento, em uma dialética entre a frequência e a espessura dos movimentos característica do período atual (Santos \& Silveira, 2001).

Como exemplo de um sistema de objetos técnicos fixo que possibilita o fluxo de mercadorias e a ação do consumo, pode-se mencionar o Shopping Dom Pedro (Campinas-SP). Construído durante o ano de 2002, agregou investimentos próximos aos $\mathrm{R} \$$ 300 milhões. Compreende uma área total de $750 \mathrm{mil}$ $\mathrm{m}^{2}$, sendo $105 \mathrm{mil} \mathrm{m}^{2}$ de área locável, onde realiza-se o comércio de uma grande variedade de produtos e a prestação de serviços diversos, o que inclui: lojas de conveniência, concessionárias de automóveis, um supermercado, bancos, serviços de documentação civil, 15 salas de cinema, uma mega store de cultura, uma casa de espetáculos, uma casa noturna, áreas de entretenimento e uma ampla praça de alimentação. A gestão centralizada possibilita reduções de custos e de encargos burocráticos aos lojistas, já que todos os trâmites são tratados por uma equipe especializada na sede da empresa, na cidade de São Paulo. Para além do projeto arquitetônico e paisagístico, a organização do prédio destaca-se pela precisão que oferece às operações logísticas. Seu grau de automação permite classificá-lo como edifício inteligente, já que encontram-se unificados os sistemas elétrico, hidráulico e de ar condicionado, além do circuito fechado de TV. Esse objeto situa-se estrategicamente às margens da rodovia Dom Pedro I, que conecta Campinas ao interior do estado - Itatiba e Atibaia - e à via Dutra, que faz ligação com o Vale do Paraíba e o Rio de Janeiro. A rodovia Dom Pedro I possibilita acesso também ao complexo AnhangueraBandeirantes, que comunica Campinas a São Paulo, passando por Jundiaí. Já a rodovia Campinas-MogiMirim liga a rodovia Dom Pedro I ao Circuito das Águas Paulista e ao sul de Minas Gerais. Sua construção foi acompanhada pela grande mídia, fato que causou expectativas na população, que 
compareceu em massa ao local no dia da inauguração (Manetta, 2003).

Vinculados à existência de complexos circuitos espaciais de produção e extensos círculos de cooperação, os shopping-centers são o produto de grandes investimentos imobiliários que modificam a estrutura e o dinamismo das grandes cidades e regiões metropolitanas, despontando como uma instância relevante da cadeia de distribuição de produtos e serviços, incluindo diversos tipos de lazer e de consumo cultural. Suas funções entram em sincronia com a expansão e diversificação dos consumos imateriais, o que inclui a educação, a saúde, a religião, as viagens, as feiras, as manifestações artísticas, os congressos e todo um leque de serviços promovidos por um intenso trabalho de marketing e propaganda, capaz de difundir e justificar padrões de comportamento que cada vez mais se instalam na sociedade brasileira. Existem, contudo, modos de resistência à generalização dessa psicoesfera de controle da vida social, fundados em formas variadas de viver e de fazer que coexistem com os padrões comportamentais característicos da globalização. Exemplos podem ser encontrados na educação, na culinária, nas tradições, nas emissoras locais de rádio e de televisão (Santos \& Silveira, 2001).

Com relação aos circuitos espaciais globalizados de produção, torna-se importante distinguir entre a ação dos que decidem e a ação dos que executam. Um decididor é aquele que pode escolher o que vai ser difundido e, muito mais, aquele capaz de escolher a ação que, nesse sentido, vai realizar-se. As decisões, mesmo que de origem distante, constituem normas de uso dos sistemas técnicos presentes, influenciando a conduta e padrões de comportamento. A escala da decisão tende a alcançar lugares diversos espalhados pelo planeta, enquanto a escala da execução sempre é o lugar. Nesse caso, o que acontece é o controle remoto da parcela política da produção e o controle local da parcela operacional. A escolha do homem comum, em muitas das ações que empreende é, destarte, limitada, já que figura apenas como veículo da decisão e não como o seu verdadeiro motor. Esse processo de distanciamento entre a sede da decisão e a sede da execução, poderia, assim, ser entendido como um processo de alienação dos lugares. Os resultados da ação humana, entretanto, não dependem unicamente da racionalidade da decisão e da execução, já que sempre há uma quota de imponderabilidade, de modo que os agentes tendem a engajar-se, também, em ações que não derivam diretamente de decisões de origem exógena (Santos, 1996).
Nas cidades, a banalização do objeto técnico cria uma mecânica normativa rotineira quase sem surpresas, cravando no tecido urbano áreas luminosas constituídas ao sabor da modernidade, que justapõem-se, superpõem-se e ao mesmo tempo se contrapõem aos espaços opacos onde vive a maioria pobre. Dessas normas, por seu conteúdo jurídico, técnico e científico, e por sua busca pela precisão no processo produtivo, diz-se que são complexas. Entretanto, pode-se também dizer que na economia dos pobres as divisões do trabalho, consideradas mais simples pelo discurso dominante, são, de fato, mais complexas. Por serem diversos, os pobres abrem debates igualmente diversificados, através dos quais ocorrem reavaliações constantes e sucessivas, tanto da tecnoesfera quanto da psicoesfera presentes, abrindo-se passo para novos usos de objetos e técnicas coexistentes nas cidades, através de inesperadas formas de cooperação social e do trabalho (Santos, 1996).

Por esse motivo, o planejamento direcionado às empresas não pode dar conta da complexidade do fenômeno urbano, já que os setores populares não absorvem imediatamente, sem contradições, os projetos e impulsos provenientes dos circuitos globais da economia, da política e da cultura. Sendo assim, a ação estritamente gerida e administrada não esgota o dinamismo e a vitalidade social, que preserva o agir consciente e fomenta âmbitos inusitados da vida urbana. As ações de ordem global, ao exercerem uma opressão sistêmica no tecido social, estimulam a ação como resistência, processo cuja coerência encontra-se precisamente em lógicas próprias constituídas nos lugares, o que leva a novos modos de vida e a usos criativos dos objetos que compõem as cidades. Surge assim um tipo de ação espontânea que protesta, reivindica e adapta-se à rigidez dos sistemas de ordem global, notadamente nos espaços urbanos desvalorizados pelo capital (Ribeiro, 2000).

A ação social, ao deslocar-se para o âmago do dia-a-dia, demanda o conhecimento de esferas da vida coletiva até poucas décadas secundarizadas na reflexão sobre o capitalismo. A ação no cotidiano, assim revalorizada, é reconhecida como depositária de novas formas de conhecimento e de exercícios do poder, dentre as quais são destacadas as manifestações da cultura urbana (Santos, 1994).

De acordo com Rimbaud (1973, como citado em Santos, 1996), nas cidades, tudo se transforma em cultura, inclusive a matéria inerte. A cultura, forma de comunicação do indivíduo e das coletividades com o universo, é uma herança e um constante reaprendizado das relações profundas entre 
o homem e seu meio. Mas, de que cultura se estaria falando?

Santos $(1996,2000)$ sugere uma divisão entre cultura de massa e cultura popular. A primeira é conduzida pelo mercado, indiferente à ecologia social e às realidades locais, e responde afirmativamente aos imperativos da homogeneização racional. Já a segunda incorpora a vontade de encarar o futuro sem rompimentos com o lugar, de onde obtém a continuidade através da mudança. Seu quadro e limite são as relações estabelecidas entre o homem e o seu meio. Seu alcance potencial, entretanto, é o mundo. Representa a resistência à homogeneização e a garantia de que a conquista dos lugares pelos vetores externos jamais será completa. Em uma aproximação grosseira, a cultura popular se manifesta desde baixo, ou seja, através de divisões do trabalho emergentes originadas na ordem dos lugares. Já a cultura de massa, como ação eminentemente econômica, revelase parte integrante do circuitos de ordem global.

As classes médias, frequentemente, deixamse absorver pela cultura de massa e dela retiram argumentos para racionalizar sua existência empobrecida. Já a população excluída, sobretudo, os mais pobres, estão parcialmente isentos dessa absorção, mesmo porque não dispõem de recursos para uma sujeição completa ao consumo de bens e serviços que transmitem e asseguram essa razão hegemônica globalizada. As cidades, por serem desiguais, tendem a abrigar ao mesmo tempo uma cultura de massa e uma cultura popular, que colaboram entre si e se atritam, interferem-se e se excluem, somando-se e subtraindo-se, em um jogo dialético ininterrupto manifesto nos lugares (Santos, 1996).

Com referência nos sistemas contemporâneos de objetos e de ações, propõe-se uma reflexão sobre os círculos de cooperação especializados na elaboração e difusão de bens culturais não-globalizados, cuja existência demonstra a ação espontânea, a emergência de contraracionalidades e usos flexíveis do território das cidades. Associados à organização horizontal da ordem dos lugares, como produtos do conhecimento prático, da emoção e da comunicação, esses círculos são representados pelas casas de cultura e associações comunitárias, manifestando-se também nas feiras, nos camelódromos, nas praças e nos quintais de chão de terra batida, criando alternativas à escassez de informação, de bens, de serviços e de espaços de convivência. Ao revelarem processos específicos de solidariedade, se opõem e ao mesmo tempo se complementam aos condicionamentos globalizados na formação de novas identidades culturais.

\section{Ação espontânea, usos flexíveis da cidade e círculos de cooperação da cultura popular}

A ação espontânea, ao atuar no sentido de melhorar as condições de vida da população excluída, promove usos flexíveis das cidades e faz emergir contra-racionalidades originadas na ordem dos lugares, gerando círculos de cooperação da cultura popular. Caracterizados por uma notável maleabilidade frente às rígidas racionalidades da ordem econômica global, esses círculos assimilam as novidades, porém, valorizando a memória. Persistem modificando-se dia após dia, situando-se na base das práticas cotidianas disseminadas no espaço banal. Seu viés revolucionário reside no rompimento com as normas preestabelecidas de funcionamento do espaço racional, através do conhecimento e da subversão, gerando uma opção de desligamento, mesmo que momentâneo e pontual, da racionalidade imposta pelos sistemas globais de objetos e de ações. Refletem movimentos conscientes de agentes em direção à realização de projetos sócio culturais. São observáveis através de processos de uso e ocupação de objetos preexistentes nas cidades, como avenidas, praças, viadutos e prédios abandonados, que passam a constituir-se espaços de trabalho, de troca e de convivência, sendo reconhecíveis também por meio de práticas e de relações sociais que revelam modos inusitados de solidariedade.

Com relação à observação empírica dos círculos de cooperação da cultura popular, alguns exemplos registrados na cidade de Campinas (SP) podem ser mencionados. A Casa de Cultura Tainã, instalada em um antigo vestiário da Praça Esportiva dos Trabalhadores (Vila Pe. Manoel da Nóbrega), depois de anos funcionando exclusivamente por iniciativa comunitária, foi um dos primeiros projetos contemplados pelo programa Pontos de Cultura (MinC). Hoje, depois de sucessivas adequações, abriga uma orquestra de steel drums (Brasilsankofa, 2010), uma oficina de construção de instrumentos musicais, uma biblioteca, um estúdio fonográfico profissional - instalado na sala de motores de uma piscina desativada - e um laboratório de redes digitais e softwares-livres, sediando inúmeros eventos presenciais ou por meio da web (Casa de Cultura Tainã, 1999, 2019).

Já a Casa de Cultura Fazenda Roseira funciona sob a gestão da Associação Jongo Dito Ribeiro, entidade que representa coletivos da comunidade negra de Campinas. Em sua sede mantém um conjunto arquitetônico colonial e um bosque arbóreo com espécies exóticas e nativas, além 
de uma horta e um canteiro de ervas com finalidades medicinais, alimentares e ritualísticas. Fomenta práticas culturais e religiosas de matrizes africanas, estimulando a pesquisa, o ensino e a formação, com vistas na recuperação e preservação do patrimônio cultural afro-brasileiro. Essa associação colabora com o programa de pós-graduação lato senso em Matrizes Africanas (FACIBRA/UNIVIDA), enfatizando conhecimentos produzidos nos campos da antropologia, da etnografia, da culinária, das artes e da museologia, atuando na perspectiva da superação das desigualdades, do respeito à diversidade e da promoção da solidariedade (Casa de Cultura Fazenda Roseira, 2010). Recentemente, a gestora da casa, Alessandra Ribeiro, foi anunciada como précandidata à prefeitura de Campinas. Por seu histórico de atuação cultural, religiosa, política e acadêmica, aparece como representante das comunidades mais excluídas da cidade (Instituto da Mulher Negra, 2020).

Outros exemplos de solidariedade chamam a atenção da mídia e da sociedade, possibilitando um olhar sob o enfoque dos círculos de cooperação da cultura popular. Esse é o caso da tradicional feira boliviana da praça Kantuta, cujo direito de realização foi conquistado no ano de 1983, através de uma negociação envolvendo a comunidade de imigrantes, a administração pública e a população local. Por meio da gastronomia, do artesanato e da música, aos domingos essa feira propicia trabalho, momentos de convivência e a preservação da memória ancestral de criollos, quéchuas, guaranis e ayamarás, tornando-se símbolo da identidade, integração e diversidade dos bolivianos presentes na cidade de São Paulo (Silva, 2005).

A União dos Moradores e do Comércio de Paraisópolis (UMCP) (São Paulo-SP), constitui outro exemplo, cuja ação, há décadas, vem ganhando notoriedade na mídia nacional e internacional. Criada a partir do reconhecimento das demandas sociais, atua voltada à melhoria das condições de vida na comunidade. Com o apoio de empresários e do poder público, desenvolve programas habitacionais, educativos, de saúde coletiva, de qualificação profissional e de inserção laboral. Recentemente, a UMCP anunciou a criação do Banco Paraisópolis, com moeda própria e linhas de crédito para autônomos, pequenos e microempresários da região. Com a concessão de empréstimos a baixos juros, pretende estimular a economia local (Machado, 2018).

Por esse histórico, Paraisópolis tornou-se referência na elaboração e aplicação de políticas sociais comunitárias, fator relevante, inclusive, no enfrentamento à pandemia do Covid-19, deflagrada no Brasil desde março de 2020. Frente à falta de políticas públicas específicas para comunidades, a UMCP organizou seus moradores, elegendo 420 presidentes de rua que monitoram diariamente cerca de 21 mil domicílios. Todos esses voluntários passaram por treinamento para a realização de tarefas, como: a conscientização sobre a importância do isolamento social; a distribuição de produtos alimentícios e de higiene; o combate à disseminação de fake news e a prestação de primeiros-socorros, quando necessário. Uma equipe formada por dois médicos, três enfermeiros e dois socorristas foi contratada com recursos próprios, juntamente com três ambulâncias - uma UTI e duas básicas. A partir do convênio com um hospital público, duas escolas estaduais passaram a abrigar 500 leitos para o isolamento de moradores infectados ou com suspeita de infecção pelo novo coronavírus. Por meio de redes de comunicação estabelecidas, essa estrutura passou a ser replicada, em algum grau, em mais de 350 comunidades espalhadas pelo Brasil (Paulo, 2020).

Outro aspecto dos círculos de cooperação da cultura popular merece uma menção particular e faz referência às cosmologias de origem indígena e africana, constituintes de razões não-hegemônicas sobreviventes na ordem dos lugares. A capoeira angola, por exemplo, adquiriu contornos de resistência cultural desde o período colonialescravagista, sobrevivendo ao Império e às Repúblicas Velha, Nova e Contemporânea. Seus saberes e rituais estão assentados em razões de origem predominantemente bantu (Terreiro de Griôs, 2016). Sua expressão atual, entretanto, demonstra adaptações constantes e sucessivas, através de um processo de modernização incompleta, encontrando sentido como ação de libertação perante as desigualdades sociais e as imposições da razão hegemônica.

$\mathrm{Na}$ capoeira angola, os ensinamentos são difundidos em espaços públicos e privados, de acordo com as tradições dos antigos mestres, mantendo-se referências a sua ancestralidade africana, porém, em sintonia com o contexto presente. Sua prática estimula a individualidade de tal maneira que o indivíduo sente-se convidado a contribuir com a coletividade a partir de suas próprias particularidades, fortalecendo tanto sua existência pessoal quanto a própria expressão coletiva da capoeira. Ao constituir um saber dinâmico e atualizado, gera processos de subjetivação ligados a uma autoafirmação existencial que se opõe à opressão das relações capitalistas, cuja expansão tende à alienação dos sujeitos com relação a sua história, ao seu cotidiano e ao seu próprio 
corpo. Por seu potencial emancipatório, a capoeira angola tem sido interpretada como um caminho para a descolonização no plano da produção de intersubjetividades, seja na esfera da expressão corporal, musical, poética ou intelectual (Silva, 2017; Cajigas-Rotundo, 2008).

No que diz respeito ao exercício do colonialismo, esse é um regime considerado como o controle e a autoridade sobre um território, exercido, porém, por grupos representantes de interesses externos. A essa falta de soberania, Aníbal Quijano (1992) reconhece como uma expressão da colonialidade do poder, que transcende particularidades históricas e não desaparece com a descolonização política, tratando-se de um processo presente que atualiza as condições de submissão diante de poderes exógenos. Como parte integrante do contexto global, a colonialidade do poder está, portanto, ativa, e afeta a todos os espaços concretos de dominação, em sintonia com as particularidades da globalização. Sendo assim, mesmo que os atributos dos colonizadores europeus dos séculos XV e XVI não sejam iguais aos padrões demonstrados pelos agentes hegemônicos da atualidade, a perversidade de sua ação dominadora permanece sempre a mesma (Souza, 2019).

T.C. Silva, presidente da Casa de Cultura Tainã, afirma que a grande mídia deve ser entendida como um meio sutil de colonização, que adentra a mente das pessoas para que obedeçam aos seus comandos transmitidos, tornando-se cativas de interesses que exercem o controle sobre seus sonhos e desejos. Já a comunicação de origem africana, por outro lado, obedece a uma tradição de respeito ao outro que permite a expressão dos sentimentos e das necessidades individuais e coletivas. Ao proporcionar o transe e a transcendência, através do canto, da música e da dança, estimula sentidos que retiram as pessoas de seu cotidiano limitado e as põem em comunhão com o universo (Duas Marias do Conhecimento, 2016).

Processos semelhantes podem ser notados com relação à prática de religiões de origem afrobrasileira, cujas cosmologias, embora modernizadas, oferecem visões particulares e heterogêneas sobre o mundo, remetendo-se a diferentes nações africanas, como as nações Angola, Jeje e Ketu (Farias et al., 2005), abrangendo a diversidade, inclusive, de manifestações de origem ameríndia, como são as linhas de caboclos tupinambá das casas de umbanda e candomblé.

Com relação à expressão intelectual indígena, Adilson Krenak considera que o sistema colonial-branco-europeu, imposto a seus antepassados, continua até hoje constrangendo a todos, levando a uma sobrevalorização do dinheiro e a uma redução das capacidades crítica e criativa das pessoas. Primeiro, os vales e campinas foram cercados, os caminhos da vida selvagem foram interrompidos e os rios contaminados. A diversidade étnica e biológica foi aniquilada, ou quase. Aos sobreviventes, restaram os internatos e as reservas, para confiná-los. Leis e mais leis foram promulgadas, assim como códigos de conduta moral que atuam para podar as liberdades existenciais e impor o negócio capitalista. Esse tipo de humanidade, ao qual somos todos impelidos a participar, demonstra nossa imersão na colonialidade e um nocaute da noção de cidadania. A percepção dessas condições, entretanto, abre brechas para a tomada de uma postura crítica no momento atual, quando as tradições devem ser valorizadas, sobretudo, com relação ao futuro, pois, hoje, representam refúgios desse mundo complicado, mostrando caminhos para a sanidade mental, nos terreiros e casas de reza, criando-se espaços transcendentais onde cantam e dançam reis, rainhas, chefes e guerreiros, em um estado de plenitude capaz de promover a cura física e psicológica, liberando pensamentos e formas de ação criativa (UnBTV, 2019).

Com referência nos discursos e conhecimentos produzidos desde racionalidades contra-hegemônicas, e com base nas considerações de Quijano (1992, p. 14-19), é preciso dar continuidade ao processo de liberação da reflexão, da comunicação e da produção do conhecimento, com relação às implicações postas pelo sistema econômico capitalista. Em outras palavras, é preciso descolonizar-se. Para tanto, a diversidade deve ser reconhecida desde pontos de vista não-hierárquicos, como componente de um todo social apoiado na heterogeneidade, pressupondo-se a existência e a copresença de diferentes lógicas articuladas em torno de uma razão hegemônica, porém, de modo nenhum única.

O livro de Davi Kopenawa e Bruce Albert (2019, como citado em Krenak, 2019), por exemplo, oferece um extenso testemunho sobre a cosmologia yanomami, demonstrando como, nessa espécie de fim-de-mundos, uma constelação de povos e culturas seja ainda capaz de habitar diferentes lugares do planeta, ao mesmo tempo em que coabitam uma cosmovisão na qual tudo toma sentido, inclusive, a presença do sistema branco-europeu.

Ressalta-se a importância dos círculos de cooperação da cultura popular como portadores de uma imensa riqueza criativa, solidária e comunicativa, cujas expressões oferecem interpretações particulares 
sobre o cotidiano e o mundo. Como subprodutos de uma modernização incompleta e seletiva, representam caminhos para a inclusão de parcelas excluídas da sociedade, encontrando-se fortemente atrelados às rugosidades iii e aos impulsos que organicamente chegam aos lugares, fato que os torna legítimos e singulares em cada manifestação específica. Ao reconhecerem a diversidade, assimilam novas formas e concepções, inclusive, impulsos provenientes dos circuitos de ordem global, o que demonstra sua maleabilidade.

Ao mesmo tempo, existe um processo de transferência de conceitos e de padrões estéticos, criados nos lugares, para contextos ampliados de produção e circulação, quando os bens culturais populares ganham valor comercial e tornam-se mercadoria. As festas e os costumes do povo, ao serem assim transformados, metamorfoseiam-se em espetáculos (Santos, 2000), festivais, livros, menus, CD's, figurinos, video-clips e oficinas (workshops), chegando mesmo a influenciar a indústria fonográfica, a moda e a propaganda, na forma de circuitos informacionais ascendentes, como tratados por Alves (2014).

A manifestação dos círculos de cooperação da cultura popular não envolve, necessariamente, uma questão econômica, seja implícita ou explícita. Sua existência, entretanto, efetiva a conformação de setores específicos da economia urbana. O movimento hip-hop, por exemplo, conta hoje com a adesão de um assíduo público consumidor de ritmos, de imagens e de comportamentos, o que corresponde também a certas modas, modos de falar e de vestirse. Esse fenômeno consagra rádios, canais de comunicação e pontos comerciais, como locais/meios de trabalho e de intercâmbio, conforme pode ser observado na Galeria Presidente (região central da cidade de São Paulo), com seus cabelereiros estilo black, suas lojas de discos e de roupas (Duarte, 2012). Em sua essência, porém, como cultura de rua, esse movimento não prescinde de modismos ou de uma relação comercial inerente, já que manifesta-se espontaneamente nas praças, nas escolas, nas esquinas e nos pontos de ônibus, através de encontros motivados pela empatia, pelos sentimentos de indignação e de rebeldia, como até hoje acontece no largo São Bento, referência histórica do hip-hop brasileiro (Pátio Metrô São Bento, 2018).

Manetta (2003), ao tratar do processo de mercantilização de bens culturais populares, utiliza como dado empírico o samba-de-bumbo campineiro. Originado nas fazendas de café do período colonial, o samba-de-bumbo foi solidário a outros batuquesde-terreiro do interior paulista, como a caiumba, a umbigada, o samba-lenço e o samba-de-roda. No começo do século XX, ainda se praticava o batuquede-terreiro em espaços públicos de Campinas, em localidades conhecidas como porteira preta, palheiro e baixada velha, sobretudo, em datas festivas como os dias de N. Sra. do Rosário e de São Benedito. Poucas lembranças, no entanto, restaram dos tempos em que o samba na rua era proibido e os encontros entre sambadores e sambadoras eram marcados pela espontaneidade dos movimentos e dos desafios de versos improvisados.

O grupo de teatro popular Urucungos, Puítas e Quinjengues, fundado pela Mestra Raquel Trindade, filha do poeta Solano Trindade, possui sede em uma estação do extinto veículo-leve-sobre-trilhos (Vila Teixeira, Campinas-SP) e preserva ainda o samba-de-bumbo, porém, de modo artístico e performático, de acordo com sua contemporaneidade (Sobrinho, 2017). Devido a um período de notável expansão do acesso aos programas públicos de promoção cultural (20022014), como o ProAC (Secretaria de Estado da Cultura-SP) e o Programa Pontos de Cultura (MinC), por exemplo, houve uma maior vinculação entre artistas populares e redes formais destinadas ao fomento da educação, da cultura e do entretenimento, como o SESI, o SENAC e o SESC. Nesse sentido, foram fortalecidos os agentes e suas manifestações, que passaram a contar com maior apoio político, técnico e financeiro para suas realizações, dinamizando-se um setor econômico especializado que valoriza a atuação de músicos, atores, dançarinos, artistas plásticos, figurinistas, diretores, pesquisadores, roteiristas, empresários, editoras e selos de gravadoras.

Nesse processo, o samba-de-bumbo, dentre outras manifestações, ganhou palco, luzes, câmeras e um mercado consumidor, através de um exercício de mercantilização e espetacularização difundido, inclusive, por meios próprios da cultura de massa. Essa difusão, entretanto, não opera de modo alienado, mas exaltando-se à vida e ao cotidiano, através de expressões com conteúdo não-globalizado, já que suas bases se encontram no lugar. A conscientização e a resistência cultural acontecem, assim, quando se procura relembrar as histórias do povo e de seus respectivos lugares, através da continuidade, mesmo que modernizada, de suas antigas tradições (Manetta, 2003).

Os círculos de cooperação da cultura popular carregam, assim, a possibilidade de inclusão de maiores e mais diversificadas parcelas da população, tanto no que diz respeito ao acesso aos bens culturais e aos programas públicos setoriais, 
quanto através da ocupação de mais diversos meios e equipamentos presentes na cidade. A cidade, ao tonar-se menos seletiva, proporciona a circulação, o encontro e o reconhecimento de novos lugares de fala, por parte de agentes de distintas orientações políticas e culturais, em um processo que vai de encontro a vivências mais plenas e democráticas.

Atualmente, entretanto, vivencia-se um acentuado processo de retrocesso das políticas públicas culturais, notadamente no âmbito do governo federal, que recentemente extinguiu o Ministério da Cultura, substituindo-o por uma Secretaria Especial da Cultura que passou a integrar o Ministério do Turismo (Sorano, 2019). Esses fatos têm levado ao aprofundamento da crise econômica e a um novo ciclo de exclusão, escassez e recessão, particularmente no que diz respeito aos setores urbanos da cultura popular, fortemente afetados pelos recortes oficiais e pela necessidade de isolamento social no contexto da pandemia do Covid-19 (Rocha, 2020).

Em situações aprofundadas de crise e de exclusão, na convivência com a necessidade e com o outro, são elaboradas políticas motivadas pela simples necessidade de existir, que nada têm a ver com a política fundada na ideologia do crescimento econômico. Nos lugares, esses dois tipos de política se encontram e se mesclam, gerando comportamentos contraditórios, suscitando expectativas e desejos, quando a figura do cidadão passa a confundir-se com a do consumidor. Nesse processo, as cidades geram uma cultura com a cara do seu tempo, mais ou menos em acordo - ou em oposição - aos donos do capital, que são também os donos do espaço e, por consequência, são os donos do tempo. Salienta-se, portanto, o fato de que os movimentos populares organizados busquem, no cotidiano das pessoas, a flexibilidade e adaptabilidade que lhes asseguram um autêntico pragmatismo existencial, constituinte maior da sua riqueza e fonte principal de sua veracidade (Santos, 2000).

Precisamente por essa riqueza e veracidade, a ação popular encerra o poder de orientar o conhecimento atualizado sobre as cidades, demonstrando, inclusive, potenciais como modelos culturais para a elaboração de conceitos abrangentes de planejamento público e comunitário. Dado o panorama atual, mais do que nunca, os círculos de cooperação da cultura popular são chamados a demonstrar seus valores, como matrizes capazes de orientar a reformulação de práticas em prol de formas mais justas, sábias e generosas de coexistência, com olhares voltados a um futuro próspero e criativo, especialmente no que diz respeito às pessoas e coletividades mais excluídas das cidades brasileiras contemporâneas.

\section{Considerações finais}

Com referência em Santos (2000), afirma-se que todo período funciona segundo uma gama de variáveis que lhe são características. A partir de certo momento, algumas delas perdem vigor, enquanto outras passam a ascender, o que permite pensar que estão sendo realizadas as condições para uma ruptura. Considerando as variáveis como elementos de subconjuntos que interagem para a formação de um conjunto total, é possível fazer referência aos círculos de cooperação da cultura popular como um subconjunto de variáveis ascendentes, direcionadas a uma ruptura com as manifestações racionais hegemônicas do atual período. Sendo assim, sua observação como matrizes de modelos para a intervenção social entra em sintonia com a noção de um incipiente período popular da história, quando as pessoas, colocadas no centro das preocupações, tomarão as rédeas da sociedade e privilegiarão ações fundadas em uma ética mais justa, como ponto de partida para novas existências individuais e também coletivas.

Considerando que os círculos de cooperação da cultura popular são constituídos por meio de divisões sociais e territoriais ascendentes do trabalho, manifestando-se através de relações sociais horizontalmente estabelecidas, reconhece-se a validade das sugestões dadas durante o processo de avaliação e revisão desse artigo, como horizonte para futuros aperfeiçoamentos. Assinala-se que este fenômeno poderia ser melhor retratado a partir da ideia de conexões geográficas (Souza, 1993), já que no mundo presente as relações entre pontos e localidades seguem rotas não-hierárquicas, e não uma rota no esquema hierárquico das redes. Além disso, são enfatizadas as possibilidades de analise dos circuitos espaciais produtivos da cultura popular, projeto que demanda estudos empíricos aprofundados, capazes de demonstrar os processos de uso do território através da descrição e mapeamento de suas respectivas conexões geográficas.

\section{Referências}

Alves, C. (2014). Os circuitos e as cenas da música na cidade do Recife: o lugar e a errância sonora. (Tese de Doutorado em Geografia). Universidade Estadual de Campinas, Campinas. 
Antongiovanni, L. (2001). Alguns nexos entre a atividade publicitária e o território brasileiro. In M. Santos \& M. L. Silveira (Orgs.). O Brasil: território e sociedade no início do século XXI (pp. 401-411). Rio de Janeiro: Record.

Brasilsankofa (2010). Orquestra Tambores de Aço na TELA 2010 - Tambores Digitais [Vídeo]. You Tube.

https://www.youtube.com/watch?v=k_Xxb I479io.

Cajigas-Rotundo, J. (2008). Capoeira Angola: vuelo entre colibríes. Una tecnología de descolonización de la subjetividad. Tabula Rasa, 9, 103-115. https://www.redalyc.org/pdf/396/3960090 7.pdf.

Casa de Cultura Fazenda Roseira (2010). Página inicial. http:/ / fazendaroseira.blogspot.com/.

Casa de Cultura Tainã (1999). Página inicial. https://www.google.com/search?q=casa $+\mathrm{d}$ $\mathrm{e}+$ cultura + tain $\% \mathrm{C} 3 \% \mathrm{~A} 3 \&$ oq $=$ casa + de + cult ura + tain $\%$ C3\%A3\&aqs $=$ chrome..69i57.4210 j0j8\&sourceid $=$ chrome\&ie $=U T F-8$.

Casa de Cultura Tainã (2019). Fábrica De Música. https:// fabricademusica.taina.net.br/2019/0 8/27/ola-mundo/.

Duarte, M. (2012). Na 24 de Maio, uma galeria dedicada à cultura black. São Paulo. Estadão. https://cultura.estadao.com.br/blogs/curioc idade/a-galeria-da-cultura-black/.

Duas Marias Conhecimento. (2016). AfroTranscendence TC Silva [Vídeo]. You Tube.

https://www.youtube.com/watch?v=7hoO mNED31Q.

Farias, J., Soares, C. \& Gomes, F. (2005). No labirinto das naçôes: africanos e identidades no Rio de Janeiro. Rio de Janeiro: Arquivo Nacional.

Instituto da Mulher Negra (2020). Historiadora Alessandra Ribeiro será a candidata do PCdoB à Prefeitura de Campinas. São Paulo, Geledés. https://www.geledes.org.br/historiadoraalessandra-ribeiro-sera-a-candidata-dopcdob-a-prefeitura-de-campinas/.

Krenak, A. (2019). Ideias para adiar o fim do mundo. São Paulo-Rio de Janeiro: Companhia das Letras.
Machado, L. (2018). Maior favela de SP terá banco e moedas próprios. São Paulo, BBC-Brasil, https://www.bbc.com/portuguese/brasil43954042

Manetta, A. (2003). Tecnoesfera e psicoesfera na dinâmica dos circuitos culturais de Campinas. (Monografia de Bacharelado em Geografia). Universidade Estadual de Campinas, Campinas.

Pátio Metrô São Bento (2018). Lango São Bento, o berŗo do hip-hop brasilein. https:/ / patiosaobento.com.br/largo-saobento-berco-do-hip-hop-brasileiro/.

Paulo, P. (2020). Paraisópolis contrata médicos e ambulâncias, distribui mais de mil marmitas por dia e se une contra o coronavírus. São Paulo, G1. https://g1.globo.com/sp/saopaulo/noticia/2020/04/07/paraisopolis-seune-contra-o-coronavirus-contrataambulancias-medicos-e-distribui-mais-demil-marmitas-por-dia.ghtml.

Quijano, A. (1992). Colonialidad y modernidad/racionalidad. Perú indígena, 13 (29), 11-20. https://www.lavaca.org/wpcontent/uploads/2016/04/quijano.pdf.

Ribeiro, A. (1991). Matéria e Espírito: o poder (des)organizador dos meios de comunicação. In R. Piquet \& Ribeiro, A. (Orgs.). Brasil, território da desigualdade: descaminhos da modernização (pp. 44-55). Rio de Janeiro: Jorge Zahar.

Ribeiro, A. (2000). Ação e seleção social: impulsos globais em contextos metropolitanos. In I. Castro (Org.). Redescobrindo o Brasil: 500 anos depois (pp. 291-300). Rio de Janeiro: Bertrand Brasil.

Rocha, C. (2020). O impacto do coronavírus na cultura. E o papel dos governos. São Paulo, Nexos.

https://www.nexojornal.com.br/expresso/2 020/03/21/O-impacto-docoronav $\%$ C3\%ADrus-na-cultura.-E-o-papeldos-governos.

Santos, M. (1994). Por uma economia política da cidade: o caso de São Paulo. São Paulo: Hucitec.

Santos, M. (1996). A natureza do espaço: técnica e tempo, razão e emoção. São Paulo: Hucitec. 
Santos, M. (2000). Por uma outra globalização: do pensamento único à consciência universal. Rio de Janeiro-São Paulo: Record.

Santos, M. \& Silveira, M. L. (2001). O Brasil: território e sociedade no início do século XXI. Rio de Janeiro-São Paulo: Record.

Santos, M., Bernardes, A., Zerbini, A., Gomes, C., Bicudo, E., Almeida, E., Contel, F., Grimm, F., Nobre, G., Antongiovanni, L., Pinheiro, M., Xavier, M., Silveira, M. L., Montenegro, M., Rocha, M. F., Arroyo, M., Borin, P., Ramos, S. \& Belo, V. (2000). O papel ativo da geografia: um manifesto. In Anais do XII Encontro Nacional de Geógrafos (pp. 1-15). http://miltonsantos.com.br/site/wpcontent/uploads/2011/08/O-papel-ativoda-geografia-um-manifesto_MiltonSantosoutros_julho2000.pdf.

Silva, D. (2017). Capoeira angola: por uma educação trans-formal. In Anais do IV Encontro Nacional de Educação (pp. 13-35). João Pessoa: Realize Editora. https://www.editorarealize.com.br/index.ph $\mathrm{p} /$ artigo/visualizar/36130.

Silva, S. (2005). A migração dos símbolos: diálogo intercultural e processos indenitários entre os bolivianos em São Paulo. São Paulo em perspectiva, $19 \quad$ (3), 77-83. https://doi.org/10.1590/S010288392005000300007.

Sobrinho, G. (2017). A dança da amižade: histórias de Urucungos, Púitas e Quïengues [Vídeo]. You Tube. https://www.youtube.com/watch?v=udtoD fLh-_Y
Sorano, V. (2019). Bolsonaro transfere Secretaria de Cultura para Ministério do Turismo. São Paulo, https://g1.globo.com/politica/noticia/2019 /11/07/bolsonaro-transfere-secretaria-decultura-para-ministerio-do-turismo.ghtml.

Souza, M. (1993). Conexões geográficas: um ensaio metodológico: uma versão ainda preliminar. Boletim Paulista de Geografia, 1(71), https://www.agb.org.br/publicacoes/index. $\mathrm{php} /$ boletim-paulista/article/view/917.

Souza, M. (1997). Cidade: lugar e geografia da existência. In Anais do V Simpósio Nacional de Geografia Urbana (pp. 1-10). http://www.belem.pa.gov.br/planodiretor/ pdfs/GEOGRAFIA_DA_EXISTENCIA_ TEXTO_MARIA_ADELIA.pdf.

Souza, M. (2019). Território usado, rugosidades e patrimônio cultural: refletindo sobre $\mathrm{O}$ espaço banal. Um ensaio geográfico. PatryTer, 2(4), 1-17. https://doi.org/10.26512/patryter.v2i4.2648 5 .

Terreiro de Griôs (2016). Ntangu-Tandu-Kolo: o conceito bantu-kongo do tempo. http://terreirodegriots.blogspot.com/2016/ 12/ntangu-tandu-kolo-o-conceitobantukongo.html.

UnBTV (2019). Diálogos: desafios para a decolonialidade [Vídeo]. You Tube. https://www.youtube.com/watch?v $=\mathrm{qFZki}$ _sr6ws

\section{Notas}

i O autor agradece aos revisores e ao comitê editorial da Revista Latino-Americana e Caribenha de Geografia e Humanidades pelas críticas, demandas e sugestões, que contribuíram imensamente para a melhoria dos resultados apresentados.

ii O termo cultural abarca simultaneamente o conteúdo de civilizações e culturas, representando todo o conjunto de bens historicamente adquirido. Esse é o sentido utilizado quando são referidos os bens culturais, ou seja, um conjunto de bens materiais e imateriais que participa igualmente da condição física e social.

iii Em geografia os sistemas de objetos herdados são denominados rugosidades. Constituem precedentes incontestáveis para as possibilidades de ação humana, de maneira que se apresentam como condição ao desenvolvimento das sociedades. É dessa maneira que a história se projeta no espaço e se reflete através de atuações sucessivas, designando a memória sobreposta das sucessivas relações e dos sucessivos modos de produção. 